\title{
TLR7 Agonist 852A
}

National Cancer Institute

\section{Source}

National Cancer Institute. TLR7 Agonist 852A. NCI Thesaurus. Code C61104.

A synthetic imidazoquinoline Toll-like receptor 7 (TLR7) agonist with immunostimulating and potential antitumor activities. TLR7 agonist 852A binds to and activates TLR7, thereby stimulating plasmacytoid dendritic cells (pDC) through the TLR7-MyD88dependent signaling pathway. Activation of pDC results in secretion of interferon alpha, the production of proimflammatory cytokines, the upregulation of co-stimulatory molecules, and enhanced T and B-cell stimulatory responses. 